\title{
Panorama das pesquisas sobre TDIC e formação de professores de língua inglesa em LA: um levantamento bibliográfico a partir da base de dissertações/teses da CAPES ${ }^{1}$
}

\section{Overview of the Researches about DICT and English Teacher Education in Al: a Bibliographical Study Based on CAPES Database of Theses and Dissertations}

Lucas Moreira dos Anjos Santos*

Monash University

Melbourne - Victoria/Australia

RESUMO: Esse trabalho tem por objetivo apresentar um panorama das pesquisas sobre Tecnologias Digitais de Informação e Comunicação (TDIC) e formação de professores de língua inglesa desenvolvidas no âmbito da Linguística Aplicada no Brasil entre os anos de 2000 a 2009. A fim de atingir o objetivo, foi realizada uma busca bibliográfica no banco de teses e dissertaçoes da CAPES a partir de termos chaves no campo assunto. Como resultados, apontamos uma ampla variedade de estudos que se voltam para tal área evidenciando diferentes focos: na transposição de políticas públicas, no uso de ferramentas digitais para formação (inicial e continuada) de professores, na apropriação de ferramentas digitais pelo professor na sua prática pedagógica, nas crenças e representações construídas a partir do uso de ferramentas tecnológicas, dentre outros. Esperamos contribuir para um mapeamento da literatura já desenvolvida na área de formação de professores de língua inglesa e TDIC para a realização de futuras pesquisas.

PALAVRAS-CHAVE: Formação de professores de língua inglesa; tecnologias digitais de informação e comunicação; levantamento bibliográfico.

* luca.dos.anjos@gmail.com

${ }^{1}$ Essa pesquisa bibliográfica foi desenvolvida como parte da minha dissertação de mestrado intitulada Gêneros digitais na educação do professor de língua inglesa como instrumentos de (trans)formação, sob orientação da professora Vera Lúcia Lopes Cristóvão no Programa de Pós-Graduação em Estudos da Linguagem da Universidade Estadual de Londrina (UEL), com bolsa da CAPES. 
ABSTRACT: This paper aims at presenting an overview of the researches about Digital Information and Communication Technologies (DICT) and English teacher education carried in Applied Linguistics in Brazil from 2000 to 2009. In order to do so, a bibliographical search was carried out at the CAPES database of theses and dissertations according to some key words related to this subject. The results point out a number of varied studies developed in this field with different focus such as: public policies and its implementation, use of digital tools in pre and in service teacher education, appropriation of digital tools by teachers into their work, believes and representations concerning the use of digital tools, among others. We hope to contribute to those who further wish to develop more studies under the theme English teacher education and DICT.

KEYWORDS: English Teacher Education; Digital Information and Communication Technologies; Bibliographical Research.

\section{Introdução}

É observável que as tecnologias digitais de informação e comunicação (TDIC, doravante) têm sido incorporadas às mais diversas esferas de atividade humana. Na esfera cotidiana, temos presenciado o crescimento e apropriação de diferentes aparelhos e recursos tecnológicos nas práticas usuais do dia a dia. Por exemplo, o aumento do uso de celulares, que permitem acesso à internet e diversas outras funcionalidades, tem sido crescente. No ano de 2011, o Brasil atingiu a marca de 242,2 milhôes de linhas móveis, totalizando uma proporção de 124 linhas para cada 100 habitantes, conforme aponta a Agencia Nacional de Telecomunicaçôes. Poderíamos mencionar ainda o uso de aparelhos de MP3 ou MP4, que têm sido utilizados desde o trajeto de ônibus do trabalho para casa à prática de exercícios físicos.

$\mathrm{Na}$ esfera do trabalho, o uso de computadores pessoais, da internet e de sistemas operacionais e softwares para realização de tarefas profissionais têm se mostrado cada vez mais inerente a nossa sociedade. $\mathrm{Na}$ esfera do entretenimento, a internet tem sido usada como um das fontes mais procuradas de uso para o lazer. Na esfera acadêmica, as buscas em provedores da rede, a disseminação de periódicos científicos e a oportunidade de contatos profissionais de forma mais acessível lideram as práticas engendradas a partir do uso das TDIC.

Por outro lado, se os aspectos positivos parecem saltar aos olhos, o número de pessoas que ainda não têm acesso às TDIC é considerável em um país de proporções continentais como as do Brasil. Segundo o último relatório do Comitê Gestor da Internet no Brasil, referente ao ano de 2010, a porcentagem de computadores por domicílio é de 39\% e a porcentagem da 
população que se diz usuária da internet é de $45 \%$. Se os respectivos números já evidenciam que nem metade da população brasileira tem acesso ainda a computadores e à internet, a desigualdade fica mais suntuosa se cruzarmos domicílios com acesso ao computador à renda das famílias. Em famílias com renda de até um salário mínimo, $6 \%$ possuem acesso; nas famílias com renda de mais de um salário mínimo até dois, esse número aumenta para 20\% (CGI.br, 2011).

Se o acesso à internet ainda é bastante restrito, as possibilidades de participação social de grupos da sociedade com menor poder aquisitivo em práticas sociais e linguageiras propiciadas pelas TDIC também são pouco animadoras. Contudo, temos presenciado essas relações antagônicas que se estabelecem a partir do(s) uso(s) e acesso às TDIC sendo alvo de debates em diferentes segmentos da sociedade: da academia a setores civis. Evidentemente, a esfera educacional não tem ficado imune a essas mudanças e tem sido convocada a repensar práticas pedagógicas de ensino e aprendizagem a partir do uso e da incorporação das TDIC.

Paralelamente, é crescente o número de estudos referentes à incorporação de TDIC no ensino e aprendizagem de línguas bem como na educação de professores. Especificamente sobre gêneros digitais, suas características e/ou seus papéis no ensino de línguas e/ou formação de professores, há uma literatura considerável que explora tais questôes na última década. ${ }^{2}$ Esse trabalho se insere nesse amplo panorama que privilegia as práticas de linguagem do meio digital e suas características em processos formativos diversos.

Nesse sentido, este artigo tem por objetivo apresentar um levantamento bibliográfico das pesquisas sobre TDIC e formação de professores em língua inglesa em LA a partir da base de dados da CAPES no período de 2000 a 2009. Para tanto, dividimos o presente texto em quatro partes: a) apresentação de pesquisas bibliográficas já realizadas na área que enfocam TDIC; b) metodologia de busca e levantamento de dados; c) agrupamento das pesquisas a partir de suas especificidades e d) discussão do levantamento bibliográfico realizado.

\footnotetext{
${ }^{2}$ A título de exemplo, conferir: MARCUSCHI; XAVIER (2004); ARAÚJO, BIASIRODRIGUES (2005); ARAÚJO (2007); ARAÚJO; DIEB (2009); ARAÚJO; DIEB; LIMA (2010); MENEZES (2010); e alguns números temáticos de periódicos sob essa temática: Trabalhos em Linguistica Aplicada, (2010, v. 49, n. 2) e Linguagem e (Dis)curso (2009, v. 9, n. 3).
} 


\section{Cenário das pesquisas de mapeamento sobre TDIC no campo da Linguística Aplicada}

O uso de TDIC nos processos de ensino e aprendizagem de línguas e em práticas diversas de letramentos tem sido alvo de diversas pesquisas na área de Linguística Aplicada (LA), conforme apontam Paiva (2005), Vieira (2004) e Lima e Lima-Neto (2009). Paiva (2005) mapeou os métodos de pesquisas com foco na interação e aprendizagem de línguas mediadas pelo computador. Segundo a autora, naquele momento havia uma lacuna no que se referia a unidades e procedimentos metodológicos para investigar as especificidades do contexto digital, assim como, evidências de aprendizagem decorrentes da comunicação mediada por computador (CMC).

Vieira (2004) mapeou os estudos sobre texto eletrônico e letramento digital, em cinco congressos brasileiros, entre 2000 e 2001. A autora ressalta que havia poucas investigações sobre essa temática (3\% do total de trabalhos) e que a maioria das pesquisas não investigava o uso das práticas de linguagem da internet em suas especificidades, mas como suporte para as mesmas questóes que já vinham sendo estudadas, como por exemplo, a motivação no contexto de aprendizagem, feedback, estratégias de leituras, entre outros. Poucos estudos se voltavam para as práticas de letramentos que emergiam e constituem o espaço virtual.

Expandindo o escopo de investigação, Lima e Lima-Neto (2009) analisaram resumos de teses e dissertações entre os períodos de 2000 a 2007 cujo foco fosse letramento digital. No levantamento realizado foram encontrados 18 resumos. Segundo os autores, os dados demonstram como os estudos sobre letramento digital são diversificados em função dos desafios que as práticas sociais e de linguagem emergentes das TDIC tem proposto. Além do mais, constataram que $38,8 \%$ dos trabalhos enfocavam gêneros digitais como objeto para produção escrita em língua materna.

De nossa parte, de modo a realizar um levantamento das pesquisas já feitas no campo da LA no Brasil sobre as relações entre TDIC e educação de professores, realizamos uma busca das teses e dissertaçóes disponibilizadas no portal da CAPES entre 2000 e 2009.

\section{Metodologia}

A busca no portal da CAPES foi realizada pelo uso de palavras-chave de acordo com os seguintes critérios: 
$>$ Primeiro, foram digitadas somente as palavras-chave e feita a busca. Dessa busca, anotamos o número de pesquisas encontradas.

$>$ Com as mesmas palavras-chave da primeira busca, realizamos uma segunda busca utilizando aspas. Nesta segunda busca, anotamos o número total de pesquisas encontradas.

$>$ Todas as demais buscas foram realizadas conforme descrito nos dois itens anteriores. Partimos sempre de palavras-chave mais amplas e fomos restringindo em função de nosso objetivo.

A primeira busca foi realizada com as palavras-chave novas tecnologias ${ }^{3}$ e formação de professores e resultou num total de 679 teses e dissertaçōes. A segunda busca foi realizada com as palavras-chave novas tecnologias e formação de professores de inglês e resultou num total 24 teses e dissertaçôes. A terceira busca foi realizada com as palavras internet e formação de professores e resultou num total de 266 teses e dissertaçóes. A quarta busca foi realizada com as palavras-chave internet e formação de professores de inglês e resultou num total de 19 dissertaçôes e teses. A quinta busca foi realizada com as palavras-chave TICs e formação de professores e resultou num total de 59 teses e dissertaçôes. A sexta e última busca foi realizada com as palavras-chave TICs e formação de professores de inglês e resultou num total de uma tese. Todas as buscas realizadas com aspas não resultaram nenhuma referência.

A partir desses dados, optamos por levantar os resumos das teses e dissertaçōes provenientes das palavras-chave: novas tecnologias e formação de professores de inglês; internet e formação de professores de inglês e TICs e formação de professores de inglês.

A partir dessa busca, categorizamos alguns elementos dos resumos, conforme o quadro abaixo, com base em Gamero (2011). Essa categorização permitiu o levantamento das principais características das pesquisas desenvolvidas na área.

\footnotetext{
${ }^{3}$ Quando realizamos essas buscas no primeiro semestre de 2010, fizemos uso do termo novas tecnologias em função de não conhecermos o termo tecnologias digitais de informação e comunicação. Optamos pelo uso deste termo depois do exame de qualificação, a partir da sugestão da banca e nossa concordância de que o termo TDIC era mais condizente com a situação contemporânea do que NTIC.
} 


\section{QUADRO 1}

Modelo de categorização dos elementos do resumo

\begin{tabular}{|l|l|l|l|l|l|l|l|}
\hline Autor & Título & Objetivo & $\begin{array}{c}\text { Referencial } \\
\text { Teórico }\end{array}$ & Metodologia & Resultados & Local & Nível \\
\hline & & & & & & & \\
\hline
\end{tabular}

A seguir, passamos a discutir as características das pesquisas encontradas.

\section{Resultados e discussão dos dados}

O total de teses e dissertações levantadas a partir dessas três categorias foi de 44. Desses 44 trabalhos, 6 não focavam formação de professores e, portanto, foram descartados do levantamento. Ainda desse total, 10 teses e dissertaçôes se repetiam, pelo menos uma vez, em alguma das buscas. Cruzando todas as buscas, portanto, tivemos um total de 28 trabalhos, sendo 25 dissertaçóes e 3 teses.

\section{Teses e Dissertações}

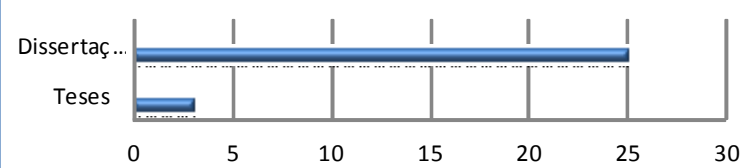

GRÁFICO 1 - Panorama das pesquisas desenvolvidas sobre TDIC e formação de professores de inglês no período de 2000 a 2009

Fonte: Banco de teses da CAPES

A partir desse panorama geral, optamos por categorizar as pesquisas também pelas instituições onde foram desenvolvidas para mapear os lugares que têm privilegiado tais estudos. Conforme pode ser visualizado, mais de 50\% dos trabalhos defendidos no período de 2000-2009 se concentram em cinco universidades brasileiras: a Pontifícia Universidade Católica de São Paulo (PUC-SP) com quatro teses/dissertaçôes, a Universidade Federal de Uberlândia (UFU) também com quatro, a Universidade Federal do Rio de Janeiro (UFRJ) com três, a Universidade Estadual do Ceará (UEC) com três e a Universidade Federal de Minas Gerais (UFMG) com duas. 


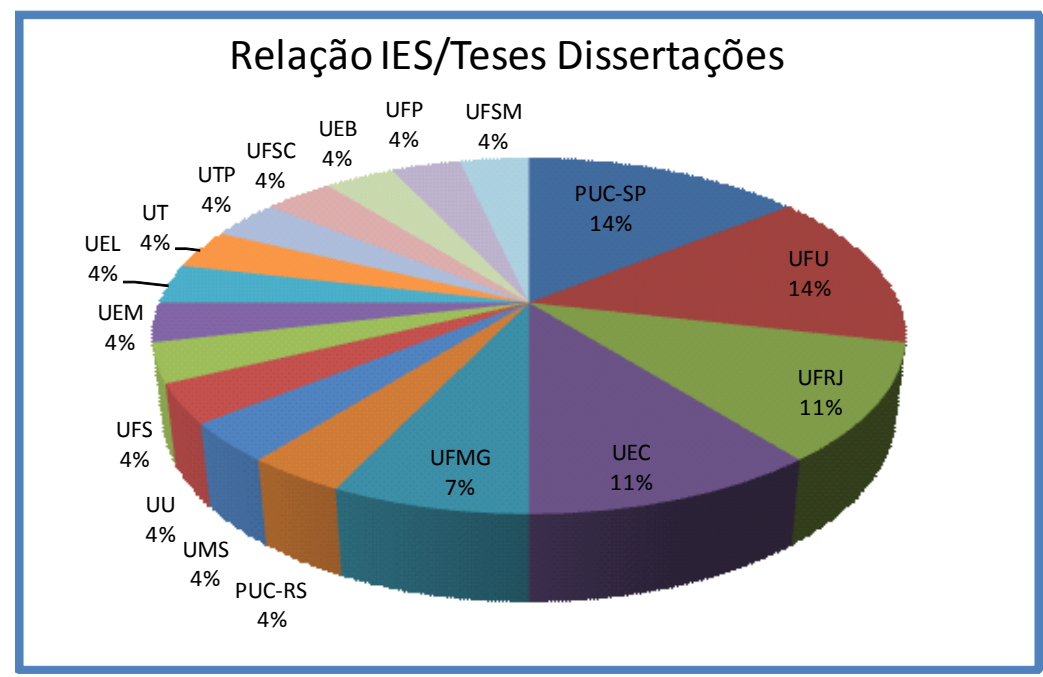

GRÁFICO 2 - Instituiçõos de Ensino Superior (IES) às quais se vinculam as teses/dissertações.

Fonte: Banco de teses da CAPES

Com exceção da Universidade Estadual do Ceará, todas as demais instituiçõos de ensino superior (IES) encontram-se localizadas no sudeste. Tal característica parece evidenciar uma concentração de interesses por esse nicho de pesquisa na referida região em função da própria constituição histórica dos programas de pós-graduação em LA no nosso país e de, ainda hoje, ser a região com maior número de pesquisadores. Apesar de não possuirmos dados consistentes para uma análise mais profunda da emergência de novas agendas de pesquisa no nosso campo, é factível inferir que as IES do sudeste ainda possuem grande representatividade na definição de nichos de pesquisa, como parece ter sido o caso com as TDIC e educação de professores. A própria concentração de acesso às TDIC por meio da internet nos domicílios brasileiros ainda é no sudeste, 36\% do total (CGI.br, 2011), o que também justifica o maior número de pesquisas com TDIC e educação de professores na região.

O gráfico, a seguir, demonstra um crescimento na produção de teses e dissertações sobre a temática pesquisada durante a primeira década do século XXI. 


\section{Teses e Dissertações/Ano}

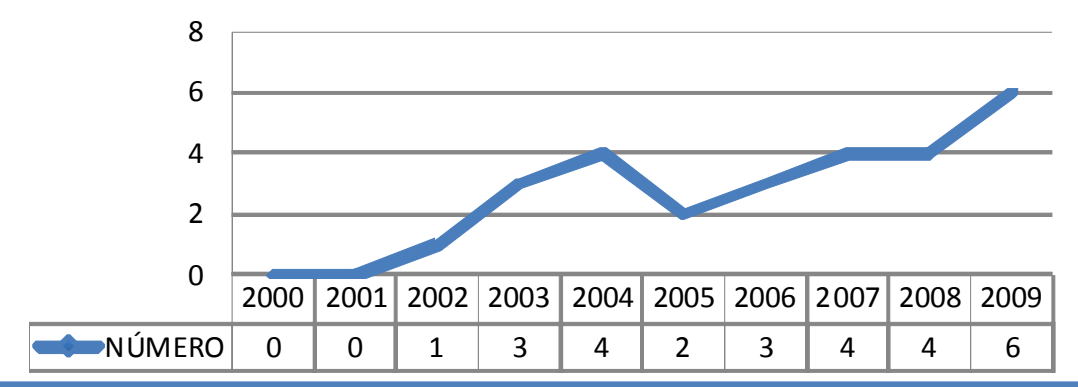

GRÁFICO 3 - Número de teses e dissertações defendidas por ano Fonte: Banco de teses da CAPES

Fica evidenciado, por meio da análise do gráfico anterior, o crescimento que pesquisas sobre formação de professores eTDIC têm tido na última década. O pico de maior número de trabalhos defendidos é de 2009, sugerindo um crescimento sobre tal temática nos próximos anos. Esse crescimento parece acompanhar tanto o aumento do número de usuários da rede (o aumento de $13 \%$ da população com acesso à rede para $45 \%$ nos últimos cinco anos no Brasil (CGI.br, 2011)) quanto a crescente demanda educacional para (re)pensarmos como as atuais práticas de ensino e aprendizagem de línguas, e portanto, de educação de professores, podem ser transformadas pelos usos de TDIC.

No que se refere aos aspectos teórico-metodológicos das pesquisas, realizamos um levantamento dos referenciais teóricos, natureza da pesquisa, instrumentos de coleta de dados e procedimentos de análise usados nas 28 teses e dissertações que compõem nosso corpus. A tabela a seguir ilustra a porcentagem de teses e dissertações que continham tais elementos em seus resumos.

\section{QUADRO 2}

Porcentagem de teses e dissertaçôes em relação aos aspectos teórico-metodológicos

\begin{tabular}{|l|c|c|c|c|}
\hline & $\begin{array}{c}\text { Referencial } \\
\text { Teórico }\end{array}$ & $\begin{array}{c}\text { Natureza } \\
\text { da Pesquisa }\end{array}$ & $\begin{array}{c}\text { Instrumento de } \\
\text { Coleta de Dados }\end{array}$ & $\begin{array}{c}\text { Procedimentos } \\
\text { de Análise }\end{array}$ \\
\hline Teses & $100 \%$ & $66,66 \%$ & $66 \%$ & $33,33 \%$ \\
\hline Dissertações & $60 \%$ & $52 \%$ & $96 \%$ & $36 \%$ \\
\hline
\end{tabular}

Fonte: Banco de teses da CAPES 
É evidente que a ausência destes elementos no resumo do trabalho não significa que não sejam contemplados no corpo do texto. Entretanto, tais características deveriam ser melhor contempladas nos resumos de modo a facilitar a própria busca por trabalhos na área.

No que tange aos referenciais teóricos adotados, o gráfico a seguir resume as opções teóricas encontradas nos resumos. É interessante notar que, apesar de alguns resumos se identificarem como fundados em determinado referencial teórico, por exemplo, nas TDIC, eles são apresentados muito mais como uma temática ampla do que um quadro teórico de base. Com base no panorama apresentado, faz-se necessário ressaltar ainda que não temos evidências que indiquem a preferência de um determinado referencial teórico para investigar a formação de professores e suas relaçôes com as tecnologias digitais.

\section{Referencial Teórico}

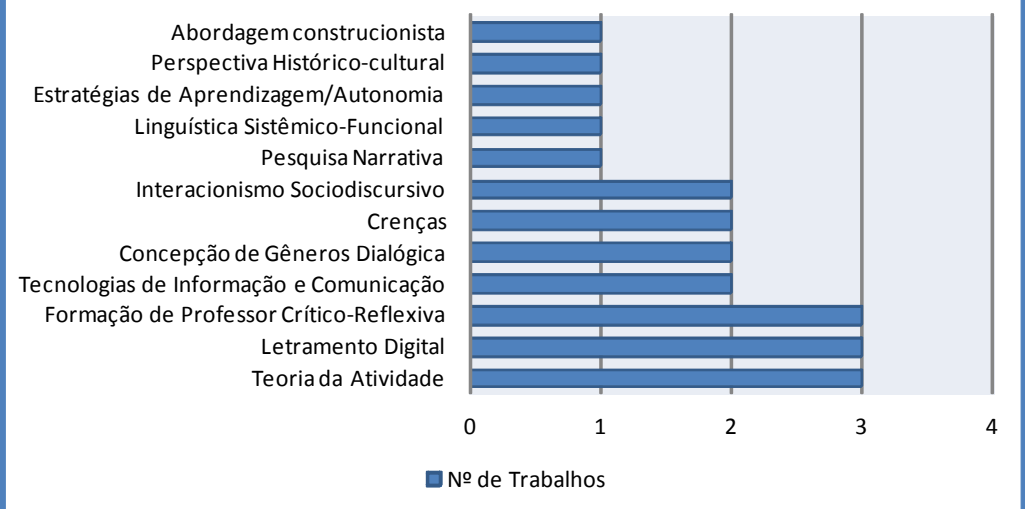

GRÁFICO 4 - Ocorrência de referenciais teóricos nas teses e dissertaçōes sobre TDIC e formação de professores

No que concerne à natureza da pesquisa realizada, há um número significativo de estudos de casos. Além do mais, não encontramos nenhuma pesquisa quantitativa pura. Houve a incidência de uma pesquisa que se intitulava como quantitativo-qualitativa. O gráfico seguinte demonstra tais afirmaçōes. 


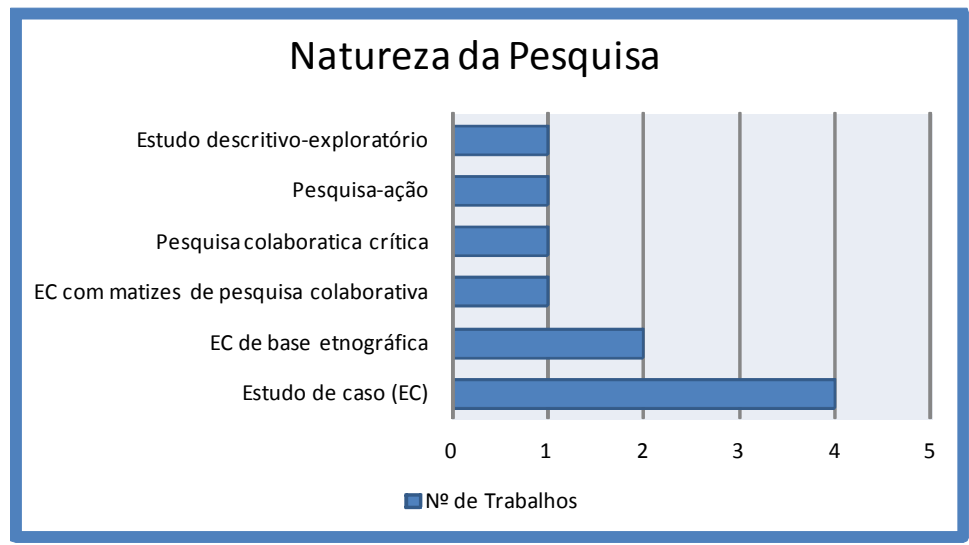

GRÁFICO 5 - Natureza da pesquisa das dissertações e teses sobre TDIC e formação de professores

Fonte: Banco de teses da CAPES

Pelo fato de haver maior concentração de trabalhos sobre a temática TDIC e educação de professores de inglês de natureza qualitativa sendo, em sua grande maioria, estudos de caso, entendemos a necessidade de se compreender como as práticas de TDIC, ao serem incorporadas pelos professores, podem (re)configurar o trabalho docente. Leffa (2006) também já apontou que os estudos de caso têm certa representatividade na área de investigaçôes relacionadas à CALL (Computer Assisted Language Learning). Além do mais, não podemos perder de vista que a maioria dos trabalhos levantados por nossa busca é em nível de mestrado, corroborando a preferência por esse tipo de pesquisa.

A partir do panorama apresentado, e com base nos resumos das teses e dissertações pesquisadas, também realizamos um agrupamento das teses/ dissertações em relação a seus focos de pesquisa e apresentamos uma síntese dos resultados e objetivos a seguir.

\section{Foco nas relações entre políticas educacionais e o uso de tecnologias digitais no ensino}

\begin{tabular}{|l|l|}
\hline \multicolumn{1}{|c|}{ Referência } & \multicolumn{1}{c|}{ Escopo de Pesquisa } \\
\hline Oliveira (2007) & $\begin{array}{l}\text { Análise do uso que professores de inglês da rede pública fazem do computador } \\
\text { e da internet na interface com formação de professores e políticas públicas. }\end{array}$ \\
\hline Paz (2003) & $\begin{array}{l}\text { Análise de projetos públicos para o uso de tecnologias digitais em sala de } \\
\text { aula e contraste com a prática pedagógica dos professores de inglês da rede } \\
\text { pública participantes desses projetos. }\end{array}$ \\
\hline
\end{tabular}


Essas são as únicas pesquisas na área de língua inglesa que privilegiam uma análise da transposição entre as políticas públicas em nível federal e sua implementação/adoção em nível municipal. Paz (2003) demonstrou que os projetos de informática não têm sido satisfatoriamente desenvolvidos nas escolas analisadas. Os professores de inglês não desenvolvem atividades pedagógicas para uso desses laboratórios e possuem uma percepção limitada de seu uso no ensino e aprendizagem. A autora ainda ressalta a falta de formação tecnológica do professor de inglês para planejar e implementar açóes com o uso de tecnologias digitais.

Analogamente, Oliveira (2007) analisou a incorporação do uso de tecnologias digitais por professores de inglês na rede municipal de ensino de Aracaju. Partindo de um panorama mundial sobre as bases do novo capitalismo e o papel da língua inglesa, a autora entrevistou nove professores. Os resultados apontam para a falta de políticas públicas que viabilizem o uso do computador no ensino de língua inglesa pelos professores.

\section{Foco no uso e/ou nas crenças sobre o uso de tecnologias pelo professor para/em sala de aula}

\begin{tabular}{|l|l|}
\hline \multicolumn{1}{|c|}{ Referência } & \multicolumn{1}{c|}{ Escopo de Pesquisa } \\
\hline Fernades (2009) & $\begin{array}{l}\text { O papel da leitura de hipertexto a partir das percepçóes de professores. } \\
\text { Análise de como um professor implementa e explora atividades com } \\
\text { hipertexto. }\end{array}$ \\
\hline Silva (2008) & $\begin{array}{l}\text { Investigação do percurso de uma professora na implementação de aulas } \\
\text { informatizadas em seu contexto. Análise do planejamento e preparo das } \\
\text { aulas assim como das aulas em si. }\end{array}$ \\
\hline Arantes (2008) & $\begin{array}{l}\text { Análise do dizer e do fazer do professor para identificar as crenças sobre a } \\
\text { influência das tecnologias digitais no ensino e aprendizagem de línguas. }\end{array}$ \\
\hline Sabariz (2004) & $\begin{array}{l}\text { Análise das estratégias usadas pela professora e alunos num curso de leitura } \\
\text { e escrita virtual com foco na autonomia }\end{array}$ \\
\hline Moreira (2004) & $\begin{array}{l}\text { Identificação das crenças e pontos de vistas dos professores em relação ao } \\
\text { uso de tecnologias digitais. Análise da apropriação dos recursos tecnológicos } \\
\text { para uso na prática pedagógica de ensino de línguas }\end{array}$ \\
\hline Campos (2002) & $\begin{array}{l}\text { Análise dos usos que os professores fazem da internet em sala de aula e dos } \\
\text { tipos de atividades e design das tarefas propostas com o uso de tal ferramenta. }\end{array}$ \\
\hline
\end{tabular}

As pesquisas elencadas sobre esse escopo abrangem a prática pedagógica do professor e uso das tecnologias digitais no ensino de língua inglesa bem com as crenças sobre o uso de TDIC. A maioria das pesquisas relatadas não tinha 
como foco a intervenção no trabalho do professor. Fernandes (2009) analisou tanto a percepção quanto a prática pedagógica de um professor de inglês de uma escola particular em relação ao uso do hipertexto. As análises demonstram que apesar de o professor ser digitalmente letrado, a transposição didática das práticas de linguagem em torno do hipertexto não ocorreu.

Silva (2008), por sua vez, analisou a informatização das aulas de uma professora da rede pública com base na Teoria da Atividade. Segundo o autor, o uso do computador como instrumento de mediação possibilitou outras formas de aprendizagem e interação. Ele ainda ressalta a necessidade de haver um suporte/acompanhamento ao professor no processo de implementação e uso de computadores em sala de aula.

Analogamente, Moreira (2004) examinou a percepção e o uso do ambiente multimídia por quatro professores de língua inglesa. Segundo a autora, a apropriação dos recursos tecnológicos à prática dos professores não alterou a maneira como ensinavam e focou-se principalmente em aspectos operacionais.

Paralelamente, Campos (2002) pesquisou os usos que os professores de inglês fazem da internet em sua prática pedagógica a partir das tarefas elaboradas por eles. Ficou evidenciado que os recursos da rede não são usados para realização de tarefas significativamente novas, mas para realização de tarefas que poderiam ser feitas sem o uso da internet. $\mathrm{O}$ autor ainda ressaltou que apesar de a maioria das tarefas serem de cunho comunicativo, elas não requeriam um engajamento significativo e crítico por parte dos alunos.

Sob outro viés, Arantes (2008) investigou as crenças de professores de um instituto de línguas sobre o uso de tecnologias digitais. Para tanto, a autora tanto os entrevistou quanto observou suas aulas para apreender o dizer e o fazer dos professores. Os resultados apontam para uma dissonância entre aquilo que é dito e o que é feito.

A partir da concepção de aprendiz autônomo, Sabariz (2004) pesquisou as estratégias de aprendizagem utilizadas por alunos e pela professora num curso de inglês online. As análises evidenciaram que as estratégias usadas pela professora e as características da comunicação mediada por computador podem favorecer ao desenvolvimento de autonomia, apesar de sua natureza complexa. 


\section{Foco no uso de tecnologias pelo professor para seu aprendizado e/ ou desenvolvimento profissional}

\begin{tabular}{|l|l|}
\hline Referência & \multicolumn{1}{|c|}{ Escopo de Pesquisa } \\
\hline Galvão (2009) & $\begin{array}{l}\text { Análise das interações de professores no gênero fórum virtual e sua } \\
\text { contribuição para formação continuada. }\end{array}$ \\
\hline Costa (2006) & $\begin{array}{l}\text { Incorporação de tecnologias digitais nas aulas de língua e análise da } \\
\text { aprendizagem do professor a partir desses usos e dos conflitos gerados. }\end{array}$ \\
\hline Magalhães (2003) & $\begin{array}{l}\text { Professores que produzem websites sobre ensino de língua inglesa. Ponte } \\
\text { de interação entre professor webmaster e professor usuário. Desenvolvimento } \\
\text { de ambos em função das possibilidades de interatividade e construção de } \\
\text { conhecimento propiciado pelo ambiente em rede. }\end{array}$ \\
\hline
\end{tabular}

Galvão (2009) analisou a participação de professores em serviço numa comunidade online de discussão. As análises das interações no fórum foram realizadas de modo a compreender a atitude responsiva dos professores nessa comunidade virtual. A autora afirma que o fórum é um espaço de formação continuada para os professores. Já Costa (2006) pesquisou o processo de aprendizagem de duas professoras (uma de Inglês e outra de Espanhol) no uso da internet e na produção de material didático por elas, em conjunto com a pesquisadora, incorporando tais recursos. Com base na Teoria da Atividade e na Reflexão Crítica, a autora analisou as contradições e conflitos do sistema de atividade gerados pelo processo de aprendizagem e ressaltou a necessidade da formação crítico-reflexiva dos professores de línguas ao incorporarem tecnologias digitais em seu trabalho.

Por fim, Magalhães (2003) investigou a produção de websites para ensino de inglês por professores. A autora entende que o espaço criado pela produção e atualização de websites é uma modalidade de formação continuada e desenvolvimento profissional.

\section{Foco na formação continuada do professor para o uso de tecnologias digitais}

\begin{tabular}{|l|l|}
\hline Referência & \multicolumn{1}{|c|}{ Escopo de Pesquisa } \\
\hline Baladeli (2009) & $\begin{array}{l}\text { Curso de extensão para professores de rede pública. Criação de um espaço } \\
\text { para aprendizagem e reflexão sobre os usos das tecnologias no ensino- } \\
\text { aprendizagem. }\end{array}$ \\
\hline Marson (2007) & $\begin{array}{l}\text { Curso sobre possibilidades didático-pedagógicas para professores de uma } \\
\text { instituição de ensino superior. }\end{array}$ \\
\hline Carvalho (2005) & $\begin{array}{l}\text { Análise das representações das professoras antes e após um curso de extensão } \\
\text { sobre o uso da internet. A aprendizagem dos professores para o uso da } \\
\text { internet. }\end{array}$ \\
\hline
\end{tabular}


As pesquisas com esse escopo são de intervenção e têm como objetivo oferecer subsídios aos professores, tanto para sua própria formação continuada quanto para o uso pedagógico em sala de aula. Baladeli (2009), por exemplo, ofertou um curso de extensão sobre as potencialidades do uso da internet e investigou o conhecimento dos professores acerca da rede mundial de computadores. Marson (2007) propôs um curso sobre os usos didático-pedagógicos da internet para professores do ensino superior e, a partir de um questionário, levantou o conhecimento e experiência prévia desses docentes sobre o assunto. A partir do curso e da avaliação dos professores, a autora identificou categorias de análise e concluiu que os usos didático-pedagógicos da internet no ensino superior podem ser positivos, caso não se restrinjam aos aspectos técnico-operacionais.

Por fim, Carvalho (2005) investigou as representações de professores de inglês sobre o uso da internet antes e após uma intervenção feita a partir de um curso de extensão. Segundo a autora, apesar das lacunas ou dos pontos negativos apontados pelos professores, eles mencionam mudanças no que se refere ao ensino e aprendizado devido ao uso da internet. Nesse sentido, Carvalho (2005) advoga a necessidade de uma formação tecnológica do professor de língua inglesa como uma possibilidade de melhoria nos processos de ensino e aprendizagem.

\section{Foco no uso de tecnologias para formação de professores}

\begin{tabular}{|l|l|}
\hline \multicolumn{1}{|c|}{ Referência } & \multicolumn{1}{|c|}{ Escopo de Pesquisa } \\
\hline Santos (2009) & $\begin{array}{l}\text { Opiniōes de professores-cursistas sobre seu percurso de aprendizagem. Análise } \\
\text { das contribuições que um curso de Letras ofertado à distância pode ter para } \\
\text { a docência presencial. }\end{array}$ \\
\hline Dias (2009) & $\begin{array}{l}\text { Aprendizagem de línguas por meio do MSN (Tandem) e sua contribuição } \\
\text { para formação inicial de professores. O papel das histórias no processo de } \\
\text { tornar-se professor por meio das tecnologias digitais. }\end{array}$ \\
\hline Miguel (2008) & $\begin{array}{l}\text { Curso online para aprimoramento profissional de professores. Análise da } \\
\text { participação dos membros por meio da construção de um senso de comunidade. }\end{array}$ \\
\hline Cordeiro (2008) & $\begin{array}{l}\text { Análise da funcionalidade da interação ocorrida em chats educacionais num } \\
\text { curso de formação continuada de professores à distância. }\end{array}$ \\
\hline Souza (2007) & $\begin{array}{l}\text { Curso online de formação de professores. Investigação da apropriação por } \\
\text { parte dos professores de ferramentas tecnológicas e desenvolvimento de } \\
\text { letramento digital. }\end{array}$ \\
\hline Queiroz (2005) & $\begin{array}{l}\text { Curso semipresencial de especialização. Análise das opiniões dos alunos- } \\
\text { professores sobre o uso de tecnologias digitais no curso de especialização que } \\
\text { cursaram. }\end{array}$ \\
\hline Lang (2004) & $\begin{array}{l}\text { Curso instrumental via internet para professores. Análise das contradições } \\
\text { emergidas no contexto do curso. }\end{array}$ \\
\hline
\end{tabular}


Santos (2009) empreendeu uma pesquisa cujo objetivo era avaliar o percurso de aprendizagem de professores em formação em um curso de educação à distância. Para o autor, os professores romperam com suas concepções tradicionais de aprendizagem e repensaram suas práticas em contexto presencial. Além do mais, para ele, os cursos à distância para formação de professores podem ser uma modalidade produtiva diante das novas exigências da sociedade em rede ou do conhecimento. Dias (2009), por sua vez, investigou o papel das interaçóes por MSN num contexto TANDEM ${ }^{4}$ de aprendizagem na formação inicial de professores de língua inglesa. Os resultados revelaram que esse é um contexto favorável à aprendizagem colaborativa e à mudança das concepções de formação do professor para uma perspectiva mais autônoma e mediada por novas tecnologias.

Miguel (2008) focou o processo de formação contínua de professores por meio da participação numa comunidade virtual. De acordo com a autora, o sentimento de pertença e a participação ativa de professores na comunidade virtual, num curso de aprimoramento profissional, foram condição necessária para o desenvolvimento de cursos via internet, mostrando a relevância da comunidade em cursos de formação contínua via rede.

Cordeiro (2008) analisou a interação de professores no gênero chat educacional de modo a identificar sua funcionalidade e eficiência. Segundo a autora, o principal problema das interaçôes analisadas era a falta de conhecimento sobre o gênero e os enquadres interacionais a serem mobilizados. Nesse mesmo sentido, Souza (2007) investigou a apropriação de recursos tecnológicos por parte de professores que participaram de um curso visando o letramento digital. As capacidades mobilizadas no curso permitiram que os professores se apropriassem das ferramentas tecnológicas de modo mais eficaz.

Paralelamente, Queiroz (2005) examinou a percepção de professores em formação que participaram de um curso em nível de especialização ofertado

\footnotetext{
${ }^{4}$ Gostaríamos de ressaltar que há um número considerável de trabalhos investigativos desenvolvidos a partir da experiência do Teletandem no Brasil, coordenado por João A. Telles, na UNESP. Em nossa busca sobre formação de professores e tecnologias digitais não encontramos mais trabalhos desenvolvidos a partir desse núcleo de pesquisa, o que justifica a não exploração dos trabalhos já desenvolvidos a partir dessa experiência. Para maiores informações sobre o projeto Teletandem, acessar: <http://www.teletandembrasil.org/home.asp>.
} 
na modalidade semipresencial. As análises revelaram as dificuldades enfrentadas a partir da oferta à distância de parte do curso e a boa receptividade dos professores em relação ao uso de novas ferramentas tecnológicas incorporadas à formação continuada. Ainda nesse nicho de pesquisa, a partir das contradiçóes inerentes à atividade humana, Lang (2004) investigou o sistema de atividades de um curso instrumental de inglês à distância e as contradiçôes que emergiram das interações no fórum público da plataforma do curso e das interações endereçadas particularmente ao pesquisador. $\mathrm{O}$ estudo evidenciou as contradições que impediram o trabalho colaborativo assim como a sensação de não pertencimento à comunidade.

\section{Foco na formação continuada do professor a partir da interação professor-ferramenta-aluno}

\begin{tabular}{|l|l|}
\hline Referência & \multicolumn{1}{|c|}{ Escopo de Pesquisa } \\
\hline Pinto (2004) & $\begin{array}{l}\text { A docência do professor formado para contextos presenciais num curso à } \\
\text { distância de inglês. Análise do processo de formação instaurado a partir da } \\
\text { experiência em ambiente digital. }\end{array}$ \\
\hline Geraldini (2003) & $\begin{array}{l}\text { Professora em formação continuada num curso via internet. Foco na atuação } \\
\text { docente. Relação entre professor-ferramenta-aluno }\end{array}$ \\
\hline
\end{tabular}

O trabalho de Pinto (2004) focalizou pela primeira vez a atuação de professores em contexto à distância. A interação entre professor, aluno e ferramentas no ambiente presencial e no ambiente digital foram tematizadas. A partir dos dados, evidenciou-se a necessidade de não transpor as práticas pedagógicas do ambiente presencial ao ambiente digital, a necessidade do aprendizado colaborativo com demais colegas e a necessidade do professor adequar sua linguagem para o contexto virtual.

Geraldini (2003), partindo da mesma perspectiva, investigou a atuação de uma professora num curso de inglês instrumental online a partir da interação professor-aluno. As ações docentes foram identificadas e confrontadas por meio de um processo reflexivo sobre a situação. Segundo a autora, a influência das sessões reflexivas na prática pedagógica da professora em contexto virtual foi evidente. 


\section{Foco na interação professor em formação-(ferramenta)-formador}

\begin{tabular}{|l|l|}
\hline Referência & \multicolumn{1}{|c|}{ Escopo de Pesquisa } \\
\hline Fischer (2007) & $\begin{array}{l}\text { Curso teórico para professores sobre o uso de tecnologias digitais. Instrumen- } \\
\text { talização do professor para o uso de tecnologias digitais em sua prática } \\
\text { pedagógica. Possibilidade de o professor vivenciar esse uso em sua própria sala } \\
\text { de aula. }\end{array}$ \\
\hline Malacrida (2006) & $\begin{array}{l}\text { Influência do curso de formação contínua oferecido pelo estado de São Paulo na } \\
\text { prática pedagógica de um professor egresso de tal curso. Relação ferramenta- } \\
\text { professor em formação-prática pedagógica. }\end{array}$ \\
\hline Juliano (2006) & $\begin{array}{l}\text { Análise da interação entre professor/máquina/aluno e os processos de } \\
\text { aprendizagem, tanto docente quanto discente, que se instauram a partir dessas } \\
\text { relações. Complexidade do sistema didático composto por essas características. }\end{array}$ \\
\hline Elias (2003) & $\begin{array}{l}\text { Investigação da formação inicial de professores para o uso de tecnologias digitais } \\
\text { a partir de documentos prescritivos e da prática pedagógica de formadores de } \\
\text { professores. }\end{array}$ \\
\hline
\end{tabular}

Fischer (2007) empreendeu uma pesquisa que visava analisar o letramento digital de professores de inglês atuantes num curso online desenvolvido e ofertado pela própria pesquisadora. A partir da vivência das professoras com questôes de cunho teórico e prático do uso de recursos tecnológicos, foram evidenciadas transformações no engajamento em práticas sociais letradas digitais. Os principais resultados foram a aprendizagem de forma colaborativa e postura crítico-reflexiva diante das questões abordadas no decorrer do curso.

Malacrida (2006), por sua vez, investigou a implementação, por parte de um professor, dos saberes apreendidos durante um curso de formação continuada à distância na sua prática pedagógica. Para a autora, os resultados evidenciam a maneira como o professor percebeu o curso vivenciado, assim como os elementos que demonstram o uso dos conhecimentos adquiridos no referido curso em sua prática de sala de aula.

Analogamente, Juliano (2006) focalizou a interação professor-máquinaaluno de modo a investigar o papel das ferramentas materiais na formação do professor e, consequentemente, na aprendizagem dos alunos. De acordo com o autor, a incorporação de tecnologias digitais às práticas dos professores ainda é precária em função da falta de conhecimento técnico e pedagógico.

Por fim, Elias (2003) pesquisou como se dá a formação inicial de professores de inglês para o uso de tecnologias digitais em sala de aula, tendo em vista as prescriçóes governamentais que sugerem o uso de tais ferramentas. 
Para ela, há um descompasso entre o que os documentos que regulam a formação do professor dizem e aquilo que efetivamente ocorre durante a formação do professor.

\section{Foco na análise de ferramenta tecnológica e seu impacto na formação de professores}

\begin{tabular}{|l|l|}
\hline Referência & \multicolumn{1}{|c|}{ Escopo de Pesquisa } \\
\hline OLIVEIRA (2009) & $\begin{array}{l}\text { Portais educacionais com atividades de leituras analisados a partir da } \\
\text { perspectiva de gêneros textuais }\end{array}$ \\
\hline
\end{tabular}

Com base nesse panorama, também foi identificada uma categoria que analisou o papel potencial da ferramenta para os professores. Oliveira (2009) investigou diferentes portais educacionais para ensino de língua inglesa e analisou as características desses gêneros e atividades de leituras propostas nesses ambientes virtuais em relação aos preceitos teórico-metodológicos subjacentes, bem como os papéis dos alunos e professores. Os resultados evidenciaram o papel reprodutor dos portais daquilo que já é produzido na mídia imprensa, além de seu papel pouco significativo na formação crítico-reflexiva dos professores.

\section{Considerações Finais}

O levantamento das pesquisas sobre formação de professores de inglês e TDIC revelou uma gama de pesquisas desenvolvidas sobre a temática e indicou que é crescente o número de trabalhos nesse nicho para os próximos anos. Todas as pesquisas se ancoram em bases qualitativas e analisam desde as políticas públicas voltadas para incorporação de TDIC na prática pedagógica do professor ao uso situado e específico de ferramentas tecnológicas pelo professor a partir de cursos de formação continuada oferecidos por pesquisadores.

Além disso, é importante ressaltar que o panorama apresentado revela que o foco das pesquisas sobre TDIC e educação de professores de inglês tem negligenciado questôes mais políticas e socioeconômicas referentes à apropriação de diferentes ferramentas tecnológicas (com exceção, talvez, das pesquisas que focaram as políticas públicas sobre TDIC e sua implementação). Pensar nos papéis das TDIC como ferramentas que podem possibilitar a emergência de espaços para a produção de contradiscursos diante de questôes sociais e culturais da sociedade (como temos tido a oportunidade de presenciar, por exemplo, o uso da rede social Twitter para agendar os lugares de protesto 
na queda do ditador egípcio ou mesmo a mobilização em diferentes redes sociais contra a proposta de regulamentação da pirataria online no senado americano) e como espaço de agência de diferentes setores da sociedade, parece ser um nicho de pesquisa ainda incipiente no que se refere ao seu impacto na sociedade e para educação de professores de línguas.

\section{Referências}

ARANTES, K. G. O ensino de língua inglesa e as novas tecnologias: a relação entre o dizer e o fazer do professor. 2008. 131f. Dissertação (Mestrado em Linguística) - Universidade Federal de Uberlândia, Uberlândia, 2008.

ARAÚJO, J. C. BIASI-RODRIGUES, B. (Org.). Interação na internet: novas formas de usar a linguagem. Rio de Janeiro: Lucerna, 2005. 174p.

ARAÚJO, J. C.; DIEB, M. (Org.). Letramentos na Web: gêneros, interação e ensino. Fortaleza: Ediçōes UFC, 2009. 287p.

ARAÚJO, J. C.; DIEB, M.; LIMA, S. C. (Org.). Linguas na web: links entre ensino e aprendizagem. Ijuí, RS: Editora Unijuí, 2010. 320p.

BALADELI, A. P. D. Desafios na formação do professor para o uso de tecnologias da informação e comunicação no ensino e na aprendizagem de língua inglesa. 2009. 125f. Dissertação (Mestrado em Educação) - Universidade Estadual de Maringá, Maringá, 2009.

CAMPOS, R. A internet e o ensino de lingua estrangeira: uma amostra de como professores de inglês estão se apropriando dos recursos da rede em sua prática pedagógica. 2002. 100f. Dissertação (Mestrado em Educação). Universidade Federal de Santa Catarina, Florianópolis, 2002.

CARVALHO, A. B. A formação docente para o uso da internet no ensino da língua inglesa: um processo de construção de significados. 2005. 208f. Dissertação (Mestrado em Estudos da Linguagem) - Universidade Estadual de Londrina, Londrina, 2005.

CGI.br. TIC domicílios e empresas 2010: pesquisa sobre o uso das tecnologias de informação e comunicação no Brasil:. São Paulo: Comitê Assessor da Internet no Brasil, 2011. Disponível em: <http://www.cetic.br/tic/2010/index.htm>. Acesso em: 10 jan. 2012.

CORDEIRO, J. M. A. A. O gênero chat educacional em ambientes de ensino a distância. 2008. 103f. Dissertação (Mestrado em Linguística) - Universidade Federal da Paraíba, João Pessoa, 2008. 
COSTA, A. P. M. Aprender a usar a Internet no ensino presencial de Inglês e de Espanhol - um estudo à luz da teoria da atividade. 2006. 192f. Dissertação (Mestrado Interdisciplinar em Linguística Aplicada) - Universidade Federal do Rio de Janeiro, Rio de Janeiro, 2006.

DIAS, N. A. A. Formação de professores de lingua estrangeira em contexto de tandem: histórias de aprender e ensinar em prática de tandem mediado pelo MSN Messenger. 2009. 162f. Dissertação (Mestrado em Linguística) - Universidade Federal de Uberlândia, Uberlândia, 2009.

ELIAS, M. G. A formação do professor de inglês para o uso de novas tecnologias. 2003. 201f. Dissertação (Mestrado em Educação) - Universidade Metodista de São Paulo, São Paulo, 2003.

FERNANDES, A. A. A leitura de hipertexto: uma análise da prática pedagógica de um docente de Língua Inglesa em laboratório de multimídia em uma escola da cidade de Fortaleza-CE. 2009. 121f. Dissertação (Mestrado em Linguística Aplicada) - Universidade Estadual do Ceará, Fortaleza, 2009.

FISCHER, C. R. Formação tecnológica e o professor de inglês: explorando níveis de letramento digital. 2007. 218f. Tese (Doutorado em Linguística Aplicada e Estudos da Linguagem) - Pontifícia Universidade Católica de São Paulo, São Paulo, 2007.

GALVÃO, C. M. M. Formação continuada de professores de língua inglesa por meio da internet: análise das interaçōes no gênero fórum. 2009. 116f. Dissertação (Mestrado em Linguística Aplicada) - Universidade de Taubaté, Taubaté, 2009.

GAMERO, R. Identidade profissional do professor de inglês: um levantamento de dissertações e teses de 1985 a 2009. In: REIS, S.; VAN VEEN, K; GIMENEZ, T. (Org.). Identidade de professores de linguas. 1 ed. Londrina: EDUEL, 2011. v.1, p. 83-103.

GERALDINI, A. F. S. Docência no ambiente digital: ações e reflexões. 2003. 245p. Tese (Doutorado em Linguística Aplicada e Estudos da Linguagem) Pontifícia Universidade Católica de São Paulo, São Paulo, 2003.

JULIANO, S. M. T. O computador no ensino da lingua inglesa e os desafios à formação docente: um estudo de caso. 2006. 183p. Dissertação (Mestrado em Educação) - Universidade de Uberaba, Uberaba, 2006.

LANG, E. L. O público e o privado: análise das contradições em um curso de leitura instrumental via internet à luz da teoria da atividade. 2004. 151p. Dissertação (Mestrado em Linguística Aplicada e Estudos da Linguagem) Pontifícia Universidade Católica de São Paulo, São Paulo, 2004. 
LEFFA, V. J. Aprendizagem de línguas mediada por computador. In: LEFFA, V. J. (Org.). Pesquisa em Linguística Aplicada: temas e métodos. Pelotas: Educat, 2006. p. 5 -30.

LIMA, S. C.; LIMA-NETO, V. Panorama das pesquisas sobre letramento digital no Brasil: principais tendências. In: ARAÚJO, J. C.; DIEB, M. (Org.). Letramentos na Web: gêneros, interação e ensino. Fortaleza: Edições UFC, 2009. p. $47-57$.

MAGALHÃES, V. B. D. S. Professores Pontocom: o que buscam e o que encontram na Web. 2003. 112p. Dissertação (Mestrado em Educação) - Pontifícia Universidade Católica do Rio Grande do Sul, Porto Alegre, 2003.

MALACRIDA, M. J. Estudo de caso de um professor participante do programa de formação contínua em serviço via internet Teacher's Links. 2006. 127p. Dissertação (Mestrado em Linguística Aplicada e Estudos da Linguagem) - Pontifícia Universidade Católica de São Paulo, São Paulo, 2006.

MARCUSCHI, L. A.; XAVIER, A. C. (Org.). Hipertexto e gêneros digitais. Rio de Janeiro: Lucerna, 2004. 196p.

MARSON, I. C. V. Ambientes virtuais de aprendizagem e docência da língua inglesa na educação superior. 2007. 199p. Dissertação (Mestrado em Educação) Universidade Tuiuti do Paraná, Curitiba, 2007.

MENEZES, V. L. (Org.). Interação e aprendizagem em ambiente virtual. Belo Horizonte: Editora UFMG, 2010. 405p.

MIGUEL, F. C. A comunidade on-line na formação contínua do professor - um estudo de caso. 161p. 2008. Dissertação (Mestrado Interdisciplinar em Linguística Aplicada) - Universidade Federal do Rio de Janeiro, Rio de Janeiro, 2008.

MOREIRA, F. H. S. Ensinar língua estrangeira na era da informação: um estudo de caso sobre apropriação do ambiente multimídia pelo professor. 2004. 278p. Dissertação (Mestrado em Linguística Aplicada). Universidade Estadual do Ceará, Fortaleza, 2004.

OLIVEIRA, A. K. C. Formação de professores para o uso das tecnologias: o caso dos professores de inglês do ensino fundamental das escolas da rede municipal de ensino de Aracaju. 2007. 118f. Dissertação (Mestrado em Educação). Universidade Federal de Sergipe, Sergipe, 2007.

OLIVEIRA, F. M. A análise de propostas pedagógicas em portais educacionais para docentes de língua inglesa: implicações para o ensino e a aprendizagem de línguas no contexto digital. 2009. 244p. Tese (Doutorado em Letras) - Universidade Federal de Santa Maria, Santa Maria, 2009. 
PAIVA, V. L. M. O. A pesquisa sobre interação e aprendizagem de línguas mediada pelo computador. Calidoscópio, São Leopoldo, v. 3, n. 1, p. 5-12, jan./ abr., 2005.

PAZ, A. M. M. O computador e o ensino de língua estrangeira: uma avaliação de projetos governamentais de informático em escolas públicas de Fortaleza. 2003. Dissertação (Mestrado em Linguística Aplicada) - Universidade Estadual do Ceará, Fortaleza, 2003.

PINTO, R. M. S. C. A formação do professor de inglês para atuar no ambiente online: a perspectiva do professor. 2004. 89p. Dissertação (Mestrado Interdisciplinar em Linguística Aplicada) - Universidade Federal do Rio de Janeiro, Rio de Janeiro, 2004.

QUEIROZ, E. S. C. Contribuiçôes do meio virtual para a educação continuada de professores de língua estrangeira (inglês): (re)pensando o paradigma educacional. 2005. 154p. Dissertação (Mestrado em Linguística) - Universidade Federal de Uberlândia, Uberlândia, 2005.

SABARIZ, S. A. Aprendizagem de lingua inglesa via internet: estratégias de aprendizagem e manifestações da autonomia do aprendiz. 2004. 210p. Dissertação (Mestrado em Estudos Linguísticos) - Universidade Federal de Minas Gerais, Belo Horizonte, 2004.

SANTOS, A. G. Vivenciado a EAD: múltiplos olhares dos aprendentes. 2009. 210p. Dissertação (Mestrado em Educação e Contemporaneidade) Universidade do Estado da Bahia, Salvador, 2009.

SILVA, D. C. A. Um estudo de caso de implementação de aulas de inglês informatizadas na escola de Ensino Fundamental. 2008. 116f. Dissertação (Mestrado em Estudos Linguísticos) - Universidade Federal de Minas Gerais, Belo Horizonte, 2008.

SOUZA, V. V. S. Letramento digital contextualizado: uma experiência na formação continuada de professores. 2007. 244p. Dissertação (Mestrado em Linguística) - Universidade Federal de Uberlândia, Uberlândia, 2007.

VIEIRA, I. L. Tecnologia eletrônica e letramento digital: um inventário da pesquisa nascente no Brasil. Revista Brasileira de Linguística Aplicada, Belo Horizonte, v. 4, n. 1, p. 251-276, 2004.

Recebido em 12/03/2012. Aprovado em 06/01/2013. 